\title{
LRG-1 enhances the migration of thyroid carcinoma cells through promotion of the epithelial-mesenchymal transition by activating MAPK/p38 signaling
}

\author{
ZHENGFENG BAN $^{1}$, JINNIAN HE ${ }^{1}$, ZHENZHEN TANG $^{1}$, LINLIN ZHANG $^{1}$ and ZHIWEN XU ${ }^{2}$ \\ ${ }^{1}$ Department of Otolaryngology Head and Neck Surgery, Second Affiliated Hospital of Guangxi Medical University, \\ Nanning, Guangxi 530007; ${ }^{2}$ Department of Otolaryngology Head and Neck Surgery, First Affiliated Hospital of \\ Guangxi Medical University, Nanning, Guangxi 530021, P.R. China
}

Received October 19, 2018; Accepted April 3, 2019

DOI: $10.3892 /$ or.2019.7123

\begin{abstract}
Leucine-rich-alpha-2-glycoprotein 1 (LRG-1) has been reported to be associated with multiple malignancies. However, its participation in thyroid carcinoma progression remains unclear. In the present study, the biological function and underlying molecular mechanisms of LRG-1 in thyroid carcinoma were investigated. It was found that LRG-1 was overexpressed in thyroid carcinoma tissues, and high LRG-1 expression predicted poor patient survival and late tumor stage. As shown in the mouse xenograft study, knockdown of LRG-1 significantly attenuated thyroid cancer growth in vivo. Based on wound healing, Transwell, proliferation and apoptosis assays, it was found that the knockdown of LRG-1, using shLRG-1, inhibited cell migration and invasion, but did not affect proliferation and apoptosis in thyroid cancer cells. Furthermore, LRG-1 also induced epithelial-mesenchymal transition (EMT) in thyroid carcinoma cells. Western blot analysis revealed that this tumor-promoting bioactivity of LRG-1 was attributed to its selective activation of MAPK/p38 signaling. All of these findings indicate that LRG-1 plays a deleterious role in the progression of thyroid carcinoma. LRG-1 may serve as a promising biomarker for predicting prognosis in thyroid carcinoma patients, and LRG-1-based therapy may be developed into a novel strategy for the treatment of thyroid carcinoma.
\end{abstract}

Correspondence to: Dr Zhiwen Xu, Department of Otolaryngology Head and Neck Surgery, First Affiliated Hospital of Guangxi Medical University, 6 Shuangyong Road, Nanning, Guangxi 530021, P.R. China

E-mail: zhiwenxugxmu@163.com

Key words: thyroid carcinoma, leucine-rich-alpha-2-glycoprotein 1, LRG-1, epithelial-mesenchymal transition, MAPK/p38, biomarker

\section{Introduction}

Thyroid carcinoma is the most common endocrine malignancy and its incidence is constantly increasing worldwide $(1,2)$. Most types of thyroid cancer usually have good prognoses owing to their well-differentiation and low malignant biological behavior as well as the ability to absorb radioiodine (3). However, a small number of thyroid cancer patients develop radioactive iodine-resistant tumors and demonstrate aggressive behavior and/or distant metastasis, significantly reducing the survival rate (4). Over the last several decades, numerous genetic alterations involved in thyroid cancer development have been identified, including point mutations of $B R A F$ and the $R A S$ genes (5), as well as fusions involving the RET and NTRK1 tyrosine kinases (6). However, a greater understanding of the mechanisms regulating tumor malignant biological behavior in aggressive thyroid cancer is still needed.

Research has demonstrated that the invasion and metastasis of malignant tumors, including thyroid cancer, are largely due to the epithelial-mesenchymal transition (EMT) process of cancer cells, and this process is considered as a critical early step in cancer progression (7). In normal thyroid tissue, epithelial cells show apical-basal polarity, they adhere and communicate with each other through specialized intercellular junctions, and they are positioned on a basement membrane that helps to define their physiology (8). During the process of EMT, epithelial cells lose their characteristics of cell polarity and adhesion, acquiring a motile mesenchymal phenotype (9), which results in enhanced mobility and invasiveness in carcinoma cells $(10,11)$. Additionally, cells that have undergone EMT acquire resistance to senescence and apoptosis (12). In a study of thyroid carcinoma, EMT-related gene expression levels were significantly upregulated in anaplastic thyroid carcinoma tissues compared with those in well-differentiated thyroid cancer tissues (13), which indicated that EMT plays an important role in the aggressive biological behavior of thyroid cancer cells. Recently, many studies revealed different regulatory mechanisms of EMT in thyroid cancer cells. For instance, SDC4 gene silencing inhibited thyroid cancer cell EMT via the Wnt/ $\beta$-catenin pathway (14). Puli et al showed that the transcription factor ETV5 decreased 
BRAFV600E-induced TWIST1 expression in thyroid cancer cells (15). In addition, microRNA-150-5p affected EMT by regulating the BRAFV600E mutation in thyroid cancer cells (16). Furthermore, lncRNA BANCR promoted EMT in thyroid cancer via the Raf/MEK/ERK signaling pathway (17).

Leucine-rich-alpha-2-glycoprotein 1 (LRG-1) is the founding member of the leucine-rich repeat (LRR) family, which was first isolated from human serum in 1977 (18). Recently, LRG-1 has been revealed as a new regulator of pathogenic angiogenesis and a novel oncogene-associated protein $(19,20)$. Reports have shown that LRG-1 is overexpressed in several types of carcinomas, such as bladder, ovarian and biliary tract cancer (21-23). Additionally, LRG-1 has an important role in glioma cell invasion and migration (24); in addition, LRG-1 was found to promote EMT in colorectal cancer via HIF-1 $\alpha$ activation (25). However, the biological function of LRG-1 in thyroid cancer and the potential molecular mechanisms of LRG-1 are still unknown.

In the present study, we examined the LRG-1 expression in human tissue samples and evaluated the prognostic value of LRG-1 in thyroid cancer patients. Next, we examined the effects of LRG-1 on proliferation, apoptosis, migration and invasion in thyroid cancer cells, and tested its function in the EMT process. Furthermore, we investigated the potential biochemical mechanisms that may be involved in the positive effects of LRG-1 on thyroid cancer invasion and metastasis.

\section{Materials and methods}

Patients and ethics statement. This retrospective study included 97 thyroid cancer patients (48 males and 49 females, aged 18-70 years) admitted to the Second Affiliated Hospital of Guangxi Medical University from January 2006 to January 2007. Patients included in this study satisfied the following criteria: i) no other organ metastasis was evident; ii) patients were diagnosed with resectable primary tumors; iii) patients presented with Eastern Cooperative Oncology Group score 0-2; and iv) patients were diagnosed with thyroid cancer by postoperative pathology. None of the patients had received previous treatment for the tumor before surgical excision. We defined patients with occurrence of relapse as the endpoint in this study. All patients included in this study had undergone total thyroidectomy with or without lymph node dissection for thyroid cancer. All patients were required to undergo a serum thyroglobulin test and an $\mathrm{I}^{131}$ body scan. Standard postoperative endocrinotherapy was applied for all thyroid cancer patients. The choice of the administration of radioactive iodine was left to the discretion of the treating physician. The baseline characteristics of these patients are shown in Table I. This study was approved by the Medical Ethics Committee of the Second Affiliated Hospital of Guangxi Medical University (no. 0010802). The study was performed in accordance with the ethical standards of the Declaration of Helsinki. Informed consent was obtained from all enrolled patients for the use of their tissues and clinicopathological data.

Histology and immunohistochemistry (IHC). For histological assessment, paraffin-embedded specimens were stained with hematoxylin and eosin (H\&E). For immunohistochemistry, sections were incubated with anti-LRG-1 antibody (dilution 1:200; cat. no. ab178698; Abcam, Cambridge, UK) overnight at $4{ }^{\circ} \mathrm{C}$, followed by incubation with HRP-conjugated secondary antibody (cat. no. KIT-5005; Maxim, Fuzhou, China) at room temperature for $15 \mathrm{~min}$. Finally, the sections were developed with 3,3'-diaminobenzidine at room temperature for 3-5 min and counterstained with hematoxylin. The intensity of staining was quantitatively analyzed with Image-Pro ${ }^{\circledR}$ Plus version 6 software (Media Cybernetics, Inc., Rockville, MD, USA). Histochemistry score (H-score) was measured to evaluate LRG-1 expression, ranging from 0 to 300 . H-scores $<200$ were classified as low expression, and scores $\geq 200$ were classified as high expression. Specifically, $\mathrm{H}$-scores were calculated by multiplying the intensity of staining ( 0 for no staining, 1 for faint staining, 2 for moderate staining, and 3 for intense staining) and the staining percentage of each core $(0-100 \%)$.

Quantitative real-time PCR ( $q P C R)$. Total RNA was extracted from fresh frozen specimens and cultured cells using a PureLink ${ }^{\circledR}$ RNA Mini kit (Invitrogen; Thermo Fisher Scientific, Inc., Waltham, MA, USA).cDNA was obtained using the PrimeScript ${ }^{\mathrm{TM}}$ RT Reagent kit (Perfect Real-Time; Takara Bio, Inc., Otsu, Japan). qPCR was performed with the ViiA ${ }^{\mathrm{TM}}$ 7 Real-Time PCR system (Applied Biosystems; Thermo Fisher Scientific, Inc.) by using the SYBR ${ }^{\circledR}$-Green qPCR SuperMix (Invitrogen; Thermo Fisher Scientific, Inc.). The thermocycling conditions were $95^{\circ} \mathrm{C}$ for $10 \mathrm{~min}$ followed by 40 cycles of $95^{\circ} \mathrm{C}$ for $15 \mathrm{sec}$ and $60^{\circ} \mathrm{C}$ for $60 \mathrm{sec}$. The $2^{-\Delta \Delta \mathrm{Cq}}$ method (26) was used to analyze the relative changes in the gene expression. GAPDH was used as a reference gene. The primers used were as follows: LRG-1, 5'-AGAACCTGAGCGACCTCTATC-3' (forward) and 5'-CACAGCGCGTGTCATTCTG-3' (reverse); CDH1, 5'-CGAGAGCTACACGTTCACGG-3' (forward) and 5'-GGGTGTCGAGGGAAAAATAGG-3' (reverse); CDH2, 5'-AGCCAACCTTAACTGAGGAGT-3' (forward) and 5'-GGCAAGTTGATTGGAGGGATG-3' (reverse); VIM, 5'-AGTCCACTGAGTACCGGAGAC-3' (forward) and 5'-CAT TTCACGCATCTGGCGTTC-3' (reverse); SNAI1, 5'-TCG GAAGCCTAACTACAGCGA-3' (forward) and 5'-AGATGA GCATTGGCAGCGAG-3' (reverse); SNAI2, 5'-CGAACT GGACACACATACAGTG-3' (forward) and 5'-CTGAGGATC TCTGGTTGTGGT-3' (reverse); ZEB1, 5'-TTACACCTTTGC ATACAGAACCC-3' (forward) and 5'-TTTACGATTACA CCCAGACTGC-3' (reverse); ZEB2, 5'-CAAGAGGCGCAA ACAAGCC-3' (forward) and 5'-GGTTGGCAATACCGTCAT CC-3' (reverse).

Western blot analysis. Protein extracts were prepared with RIPA buffer containing phosphatase and protease inhibitors. Protein concentrations were determined by BCA Protein assay. Equivalent aliquots of protein $(40 \mu \mathrm{g})$ were electrophoresed using 10\% SDS-PAGE and transferred onto polyvinylidene difluoride (PVDF) membranes (EMD Millipore, Billerica, MA, USA). The membranes were blocked with $5 \%$ skim milk for $2 \mathrm{~h}$, followed by incubation overnight at $4^{\circ} \mathrm{C}$ with specific primary antibodies against LRG-1 (dilution 1:1,000; cat. no. ab178698; Abcam, Cambridge, UK), E-cadherin (cat. no. 3195), N-cadherin (cat. no. 13116), vimentin (cat. no. 5741), p38 (cat. no. 8690) and p-p38 (dilution 1:1,000; 
Table I. Characteristics of the thyroid cancer patients.

\begin{tabular}{lc}
\hline Parameters & Data \\
\hline Age, years (mean) & $48.9 \pm 12.0$ \\
Sex, (male) $\mathrm{n}(\%)$ & $48(49.5)$ \\
Multifocality, $\mathrm{n}(\%)$ & $17(17.5)$ \\
TNM tumor stage (I/II/III), $\mathrm{n}$ & $43 / 24 / 30$ \\
LRG-1 expression (low/high) $\mathrm{n}(\%)$ & $61 / 36$ \\
Residual disease, $\mathrm{n}(\%)$ & $5(5.2)$ \\
Adjuvant radioactive iodine, $\mathrm{n}(\%)$ & $33(31.0)$ \\
\hline
\end{tabular}

LRG-1, leucine-rich-alpha-2-glycoprotein 1.

cat. no. 4511; Cell Signaling Technology, Inc., Beverly, MA, USA). After washing, the membrane was incubated with horseradish peroxidase-conjugated secondary antibody (dilution 1:2,000; cat. no. 7074; Cell Signaling Technology, Inc.) for $1 \mathrm{~h}$ at room temperature, the intensity of the protein bands was quantitatively analyzed with ImageJ $1.49 \mathrm{v}$ software (NIH; National Institutes of Health, Bethesda, MD, USA). All bands presented together were probed for on the same membrane. Considering that many different proteins (like p38, p-p38 and GAPDH) have similar molecular weight which could not be detected at the same time using one membrane, we first detected p-p38 and the same membrane was used for stripping and reprobing of the total p38 and GAPDH (27).

Cell culture. The human papillary thyroid carcinoma cell line TPC-1, the human anaplastic thyroid carcinoma cell line HTC/C3 and the thyroid squamous cell carcinoma cell line SW579 were purchased from the American Type Culture Collection (ATCC; Manassas, VA, USA). The normal thyroid-derived cell line NTHY-ORI 3-1 and de-differentiated thyroid carcinoma cell line BCPAP were purchased from Shanghai Institutes for Biological Sciences (Shanghai, China). The cells were cultured in Dulbecco's modified Eagle's medium (DMEM; Gibco; Thermo Fisher Scientific, Inc.) supplemented with $10 \%$ fetal bovine serum (FBS; Thermo Fisher Scientific, Inc.), $100 \mathrm{U} / \mathrm{ml}$ penicillin and $100 \mathrm{mg} / 1$ streptomycin, and they were incubated at $37^{\circ} \mathrm{C}$ in a humidified atmosphere with $5 \% \mathrm{CO}_{2}$. Mycoplasma testing was performed for the cell lines used. All cell lines were authenticated using short tandem repeat (STR) analysis. LRG-1 recombinant protein (cat. no. 7890-LR-025; R\&D Systems, Inc., Minneapolis, MN, USA) was used at concentrations of 100,300 or $500 \mathrm{ng} / \mathrm{ml}$ and the p38 inhibitor (SB203580; Selleck Chemicals Houston, TX, USA; cat. no. S1076) was used at a concentration of $10 \mu \mathrm{M}$.

LRG-1 knockdown in thyroid cancer cells. The LRG-1 shRNA was cloned into the pLKO.1 shRNA expression vector. Purified plasmids were transfected into 293T cells using Lipofectamine 3000 (Invitrogen; Thermo Fisher Scientific, Inc.), along with the helper plasmids psPAX2 and VSV-G. Virus supernatant was added to the cell culture in the presence of $8 \mathrm{mg} / \mathrm{ml}$ polybrene. Positive clones were obtained upon puromycin selection. The interference sequences were as follows: LRG-1 shRNA: 5'-AGCTAAAAAGATGTTTTC CCAGAATGACTCTCTTGAAGTCATTCTGGGAAAACA TCGGG-3'; Control scramble shRNA: 5'-AGCTAAAAATTC TCCGAACGTGTCACGTTCTCTTGAAACGTGACACGT TCGGAGAAGGG-3.

Cell proliferation and apoptosis assays. Cell proliferation was detected using the Click-iT $^{\circledR}$ EdU Alexa Fluor ${ }^{\circledR} 488$ Imaging kit (Invitrogen; Thermo Fisher Scientific, Inc.) according to the manufacturer's instructions. Immunofluorescence signals were captured using a Zeiss 710 laser scanning microscope (Carl Zeiss, Inc., Thornwood, NY, USA).

Cell apoptosis was measured using the Alexa Fluor $^{\circledR} 488$ Annexin V/Dead Cell Apoptosis kit (Invitrogen; Thermo Fisher Scientific, Inc.) according to the manufacturer's instructions. The samples were analyzed by flow cytometry using the CellQuest Pro software (BD Biosciences, San Jose, CA, USA).

Wound healing assay. Thyroid cancer cells were seeded in 6 -well plates up to form a $100 \%$ confluent monolayer. A wound was generated using a micropipette tip homogeneously across the monolayer, followed by washing with phosphate-buffered saline (PBS) to remove cell debris. The narrowing of the wound area was investigated at times $48 \mathrm{~h}$ and measured using ImageJ 1.49v software (NIH; National Institutes of Health).

Transwell assay. Cells at a density of $1 \times 10^{5}$ cells $/ \mathrm{ml}$ were seeded in the upper Transwell chamber (BD Biosciences) precoated with Matrigel (BD Biosciences). After $48 \mathrm{~h}$ of incubation, the cells on the upper surface of the microporous membrane were wiped off with a cotton swab, and the remaining cells were stained with $0.5 \%$ crystal violet (Sigma-Aldrich; Merck KGaA, Darmstadt, Germany) for $30 \mathrm{~min}$ at room temperature and photographed at a magnification of x200 using an Olympus IX71 inverted microscope (Olympus Corp., Tokyo, Japan). The absorbance at $570 \mathrm{~nm}$ was measured using a Tecan Infinite F500 microplate reader (Tecan Group AG, Männedorf, Switzerland).

Xenograft mouse model. In total, the 24 female BALB/c nude mice (4-5 weeks old, 18-20 g) used in this study were obtained from Shanghai Slac Laboratory Animal Company (Shanghai, China). The mice were maintained under a 12-h dark/light cycle with ad libitum access to food and water in specific pathogen-free conditions (55\% humidity and $22^{\circ} \mathrm{C}$ ). All procedures were approved by the Institutional Animal Care and Use Committee of Guangxi Medical University (no. 20186018S). The mice were randomly divided into 4 groups: The HTC/C3 cell shCtrl group, the HTC/C3 cell shLRG-1 group, the SW579 cell shCtrl group and the SW579 cell shLRG-1 group. Mice were anesthetized with $3 \%$ isoflurane. The tumor models were established by subcutaneously injecting $1 \times 10^{7}$ cell suspensions into the right upper flanks of BALB/c nude mice. Tumor volume was calculated as follows: (length $\mathrm{x}$ width $\left.{ }^{2}\right) / 2$. After four weeks, the mice were euthanatized by carbon dioxide $\left(100 \% \mathrm{CO}_{2}\right.$ gas at a flow rate 20-30\%), and tumor tissues were removed. We verified animal death through a combination of criteria, including lack of pulse, breathing, corneal reflex and response to firm toe pinch, graying of the mucous membranes, and rigor mortis. We confirm that the tumor burden did not 
A

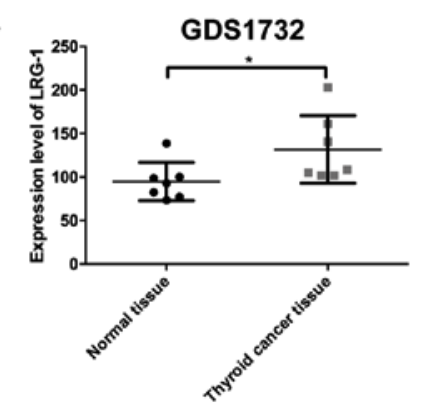

C

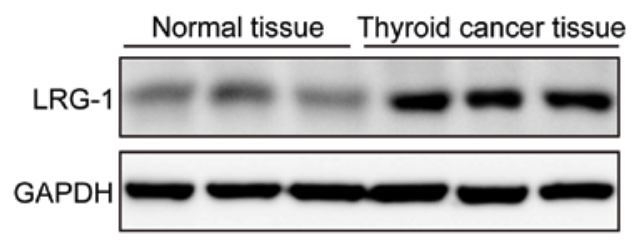

D

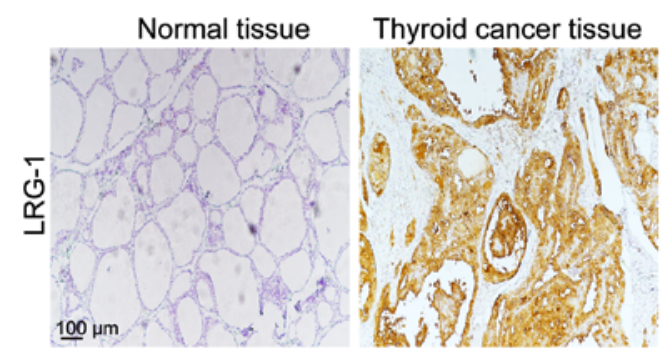

E

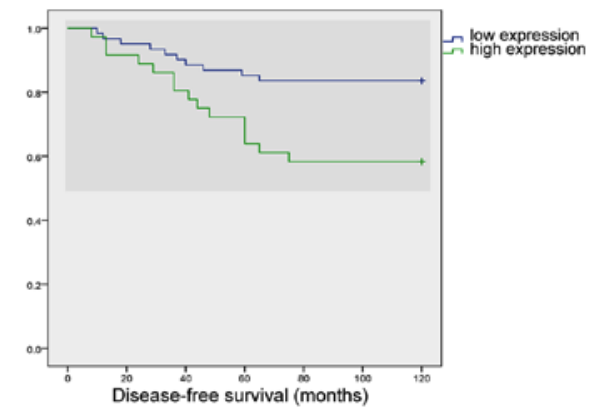

GDS1665

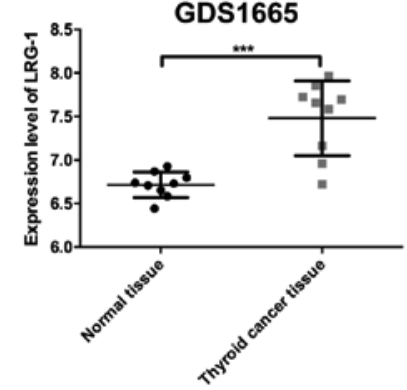

B

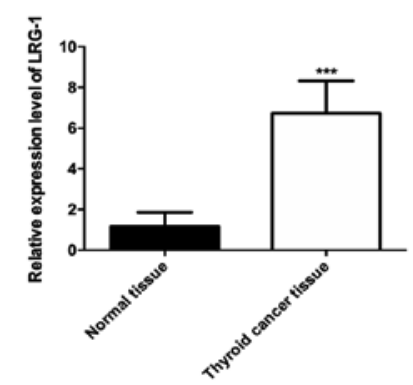

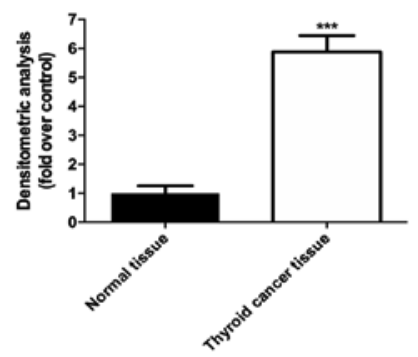

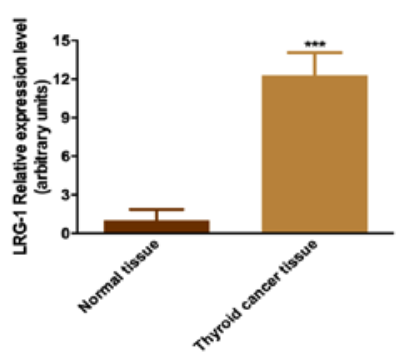

$\mathrm{F}$

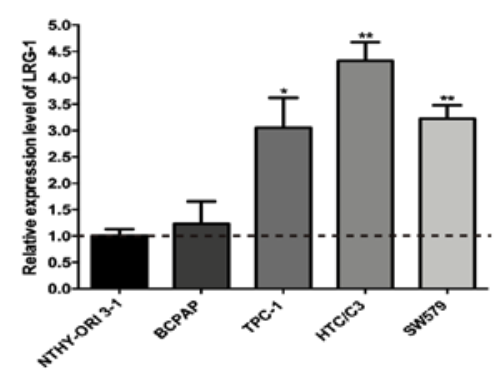

Figure 1. LRG-1 is overexpressed in thyroid cancer tissues. (A) The mRNA expression of LRG-1 in thyroid cancer tissues and normal tissues based on the microarray data from GDS1732 (7 thyroid cancer tissues and 7 normal tissues) and GDS1665 (9 thyroid cancer tissues and 9 normal tissues). (B) The mRNA and (C) protein expression of LRG-1 in normal thyroid tissues $(n=97)$ and thyroid cancer tissues ( $n=97)$. (D) Immunohistochemistry images of LRG-1 and the quantification of LRG-1 relative expression levels. Scale bars, $100 \mu \mathrm{m}$. (E) Disease-free survival analysis of thyroid cancer patients (n=97) with different LRG-1 expression levels. (F) Assessment of LRG-1 mRNA abundance in a normal thyroid cell line (NTHY-ORI3-1) and thyroid cancer cell lines (BCPAP, TPC-1, HTC/C3 and SW579) via qPCR. The horizontal dotted line represents LRG-1 mRNA levels in NTHY-ORI3-1 cells (black bar). Data are presented as the mean $\pm \mathrm{SD} .{ }^{*} \mathrm{P}<0.05 ;{ }^{* *} \mathrm{P}<0.01 ;{ }^{* * * *} \mathrm{P}<0.001$ vs. control (normal thyroid tissues or normal thyroid cell line). LRG-1, leucine-rich-alpha-2-glycoprotein 1 .

exceed the recommended size and no mouse presenting with multiple tumors was observed. The humane endpoints established in the present study were as follows: i) tumor size: Exceed $10 \%$ of body weight; ii) tumor ulceration, infection, or necrosis; iii) loss of ability to ambulate (inability to access food or water); iv) body condition score $<2$ on a 5-point scale.

Statistical analysis. The statistical analyses were performed with SPSS 20.0 (IBM Corp., Armonk, NY, USA). Data are expressed as the mean \pm standard deviation (SD) from at least three replicates. P-values $<0.05$ were considered statistically significant. We used Student's t-tests for the comparisons between two groups. One-way analysis of variance (ANOVA) followed by a post hoc test (Tukey test) was used for comparisons between two groups in multiple comparisons. Survival curves were conducted using the Kaplan-Meier method, and the significance was analyzed with the log-rank test. A Cox proportional hazards model was used to analyze the risk factors associated with disease-free survival (DFS). Clinical factors associated with LRG-1 expression were analyzed using a logistic regression model.

\section{Results}

LRG-1 expression is increased in human thyroid carcinoma tissues. To investigate the expression level of LRG-1 in thyroid 
A

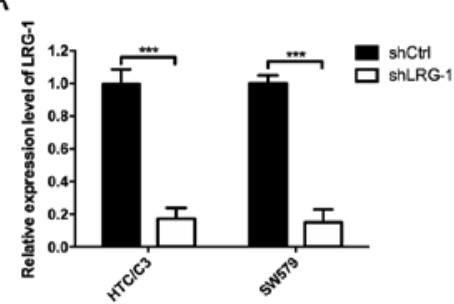

C

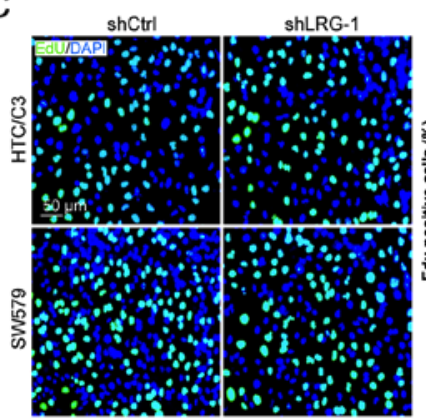

E

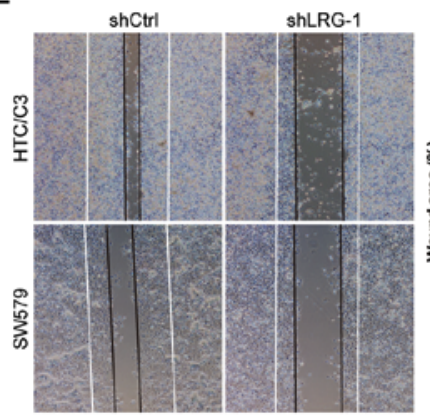

B

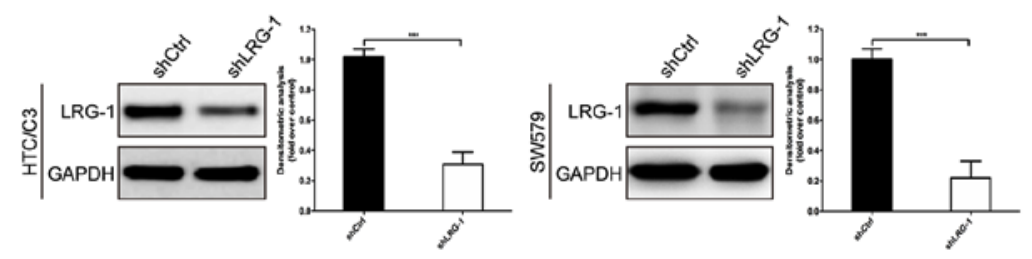

D
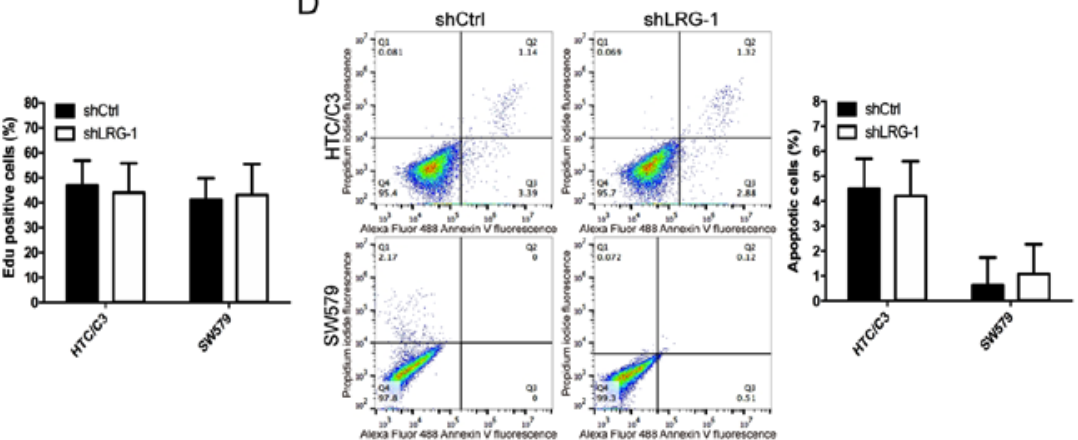

F
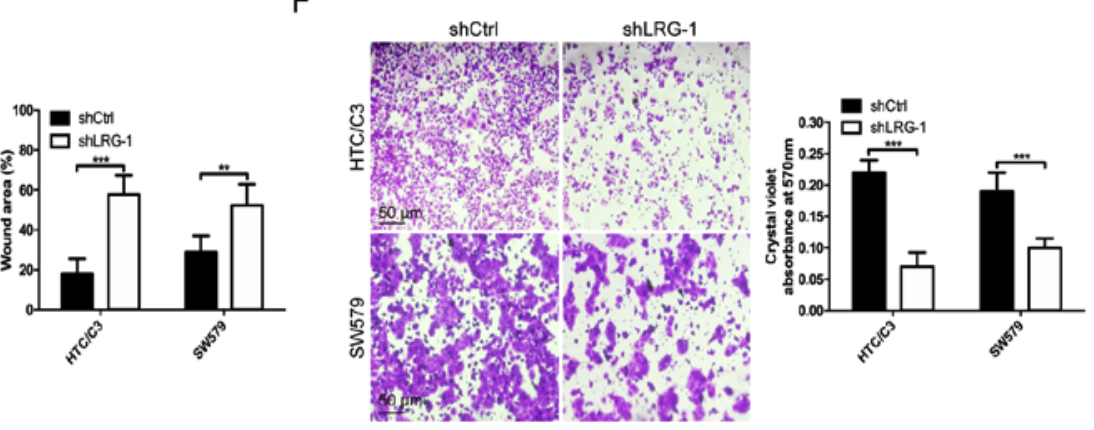

Figure 2. LRG-1 influences thyroid cancer cell migration and invasion in the thyroid cancer HTC/C3 and SW579 cell lines. (A) The mRNA and (B) protein levels of LRG-1 in HTC/C3 and SW579 cell lines as analyzed by qPCR and western blot analysis 2 days after infection with a lentivirus-expressing LRG-1 shRNA. (C) EdU (green) was used to label proliferating cells, while the nucleus was stained with DAPI (blue). Scale bars, $50 \mu$ m. (D) Apoptosis was evaluated in the thyroid cancer cell lines after shLRG-1 infection for $48 \mathrm{~h}$. The flow cytometry profile represents Alexa Fluor 488 Annexin V staining on the x-axis and PI on the y-axis. (E) Wound-healing assay and (F) Transwell cell invasion assay at $48 \mathrm{~h}$ in LRG-1-knockdown thyroid cancer cells. Scale bars, $50 \mu \mathrm{m}$. Data are presented as the mean $\pm \mathrm{SD}$ (three independent experiments). ${ }^{* *} \mathrm{P}<0.01 ;{ }^{* * *} \mathrm{P}<0.001$. LRG-1, leucine-rich-alpha-2-glycoprotein 1 .

cancer tissues, we analyzed the microarray data from two datasets GDS1732 and GDS1665 which were downloaded from the National Center for Biotechnology Information (NCBI) Gene Expression Omnibus (GEO) database (https://www.ncbi.nlm. nih.gov/geo/). The results showed that the expression level of LRG-1 was significantly higher in thyroid cancer tissues than that in normal tissues (Fig. 1A). Next, 97 thyroid cancer tissues and matched normal tissues collected at our institution were selected to detect LRG-1 expression using qPCR. A similar result was observed. LRG-1 was significantly overexpressed in thyroid cancer tissues compared with that in the corresponding normal tissues (Fig. 1B). As shown in Fig. 1C, western blot analysis and quantification demonstrated the same trend as qPCR. In addition, immunohistochemical analysis revealed that the positive staining of LRG-1 was mainly distributed in the cytoplasm and cytomembrane of thyroid cancer cells, and thyroid cancer tissues exhibited significantly increased LRG-1 expression compared with normal thyroid tissues (Fig. 1D).

High LRG-1 expression predicts poor patient survival and late tumor stage. We further analyzed the expression of LRG-1 by IHC and its association with other clinical factors in 97 thyroid cancer patients. Our data showed that late tumor stage and high LRG-1 expression were significant independent prognostic factors (Table II). Patients with higher LRG-1 levels suffered significantly worse disease-free survival (Fig. 1E). The logistic regression model analysis found that higher LRG-1 expression was correlated with later tumor stage $(\mathrm{HR}, 19.01, \mathrm{P}<0.001)$ and lymph node metastasis (HR, 43.94, P<0.001).

Knockdown of LRG-1 represses the migration and invasion capacity of thyroid cancer cells. First, we confirmed that LRG-1 expression was highly expressed in thyroid cancer cell lines. Comparing the LRG-1 expression in four human thyroid cancer cell lines with that in a normal thyroid-derived cell line (NTHY-ORI3-1), we found that 3 of 4 (75\%) thyroid cancer cell lines had greater LRG-1 transcript levels and that the expression level of LRG-1 was highest in HTC/C3 and SW579 cells (Fig. 1F and Table SI).

To determine the role of LRG-1 in thyroid cancer cell behaviors, HTC/C3 and SW579 cells were infected with lentivirus-expressing LRG-1 shRNA for the establishment of a shRNA-silenced LRG-1 stable cell line. As determined by $\mathrm{qPCR}$ and western blot analysis, both mRNA and protein 
Table II. Risk factors affecting disease-free survival.

\begin{tabular}{|c|c|c|c|c|c|c|}
\hline \multirow[b]{2}{*}{ Factors } & \multicolumn{3}{|c|}{ Univariate analysis } & \multicolumn{3}{|c|}{ Multivariate analysis } \\
\hline & HR & $95 \% \mathrm{CI}$ & P-value & HR & $95 \% \mathrm{CI}$ & P-value \\
\hline Age (<45 vs. $\geq 45$ years $)$ & 0.81 & $0.37-1.79$ & 0.603 & - & - & - \\
\hline Sex (male vs. female) & 0.89 & $0.21-3.79$ & 0.893 & - & - & - \\
\hline Multifocality (yes vs. no) & 0.56 & $0.17-1.88$ & 0.348 & - & - & - \\
\hline TNM tumor stage (I+II vs. III) & 4.65 & $2.05-10.54$ & $<0.001$ & 28.59 & $4.18-195.70$ & 0.001 \\
\hline LRG-1 (low vs. high) & 2.85 & $1.28-6.33$ & 0.011 & 1.14 & $1.02-1.92$ & 0.041 \\
\hline
\end{tabular}

LRG-1, leucine-rich-alpha-2-glycoprotein 1; HR, hazard ratio; CI, confidence interval.

A
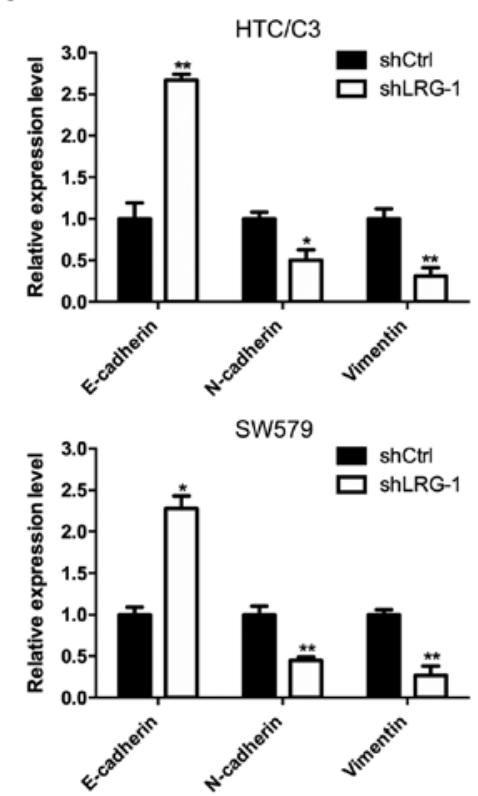

B
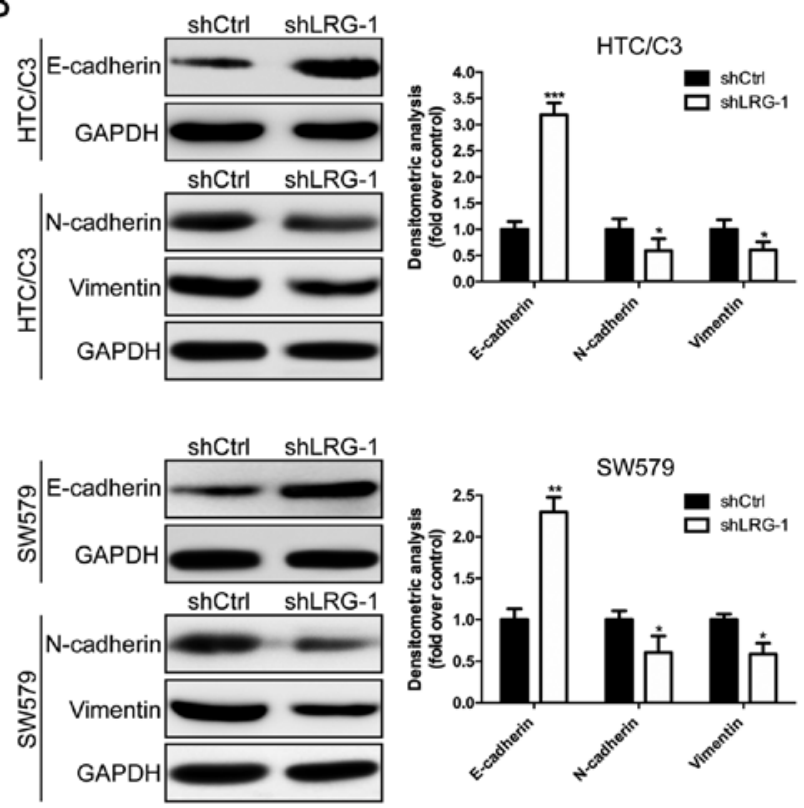

C
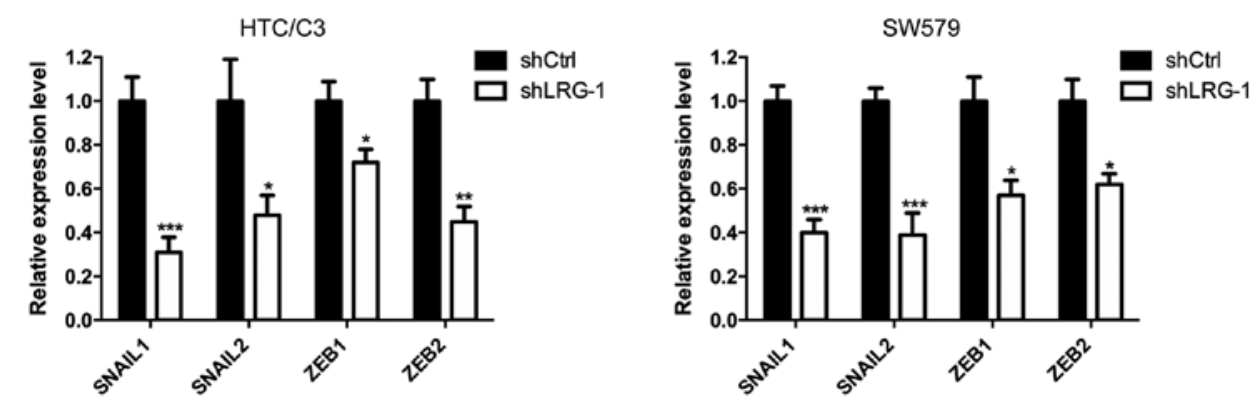

Figure 3. Knockdown of LRG-1 prevents the EMT process in the thyroid cancer HTC/C3 and SW579 cell lines. (A) The mRNA and (B) protein levels of EMT-associated markers (E-cadherin, N-cadherin and vimentin) in thyroid cancer cells transfected with shLRG-1 or control scramble shRNA were measured by qPCR and western blot assays. (C) Expression levels of SNAIL1, SNAIL2, ZEB1 and ZEB2 in LRG-1-knockdown and control thyroid cancer cells. Data are presented as the mean $\pm \mathrm{SD}$ (three independent experiments). ${ }^{*} \mathrm{P}<0.05 ;{ }^{* *} \mathrm{P}<0.01 ;{ }^{* * *} \mathrm{P}<0.001$ vs. control (shCtrl). LRG-1, leucine-rich-alpha-2-glycoprotein 1 ; EMT, epithelial-mesenchymal transition.

levels of LRG-1 were efficiently depleted in $\mathrm{HTC} / \mathrm{C} 3$ and SW579 cells following silencing (Fig. 2A and B). For proliferation detection, no significant difference in the percentages of EdU-positive cells was observed after knockdown of LRG-1 in both cell lines (Fig. 2C). Flow cytometric analysis illustrated consistent results, with the percentage of apoptotic cells remaining stable regardless of LRG-1 gene silencing (Fig. 2D). In addition, wound healing and Transwell assays were used to examine the migration and invasion abilities of the thyroid cancer cells. Our results demonstrated that the open area of the wound was significantly increased in LRG-1-knockdown cells compared with that in the control scramble shRNA 
infected cells (Fig. 2E). Likewise, in Transwell assays, the knockdown of LRG-1 significantly reduced the number of thyroid cancer cells that invaded through the membrane compared with the control (Fig. 2F). These results demonstrated that the knockdown of LRG-1 inhibited cell migration and invasion but did not affect proliferation and apoptosis in thyroid cancer cells.

Knockdown of LRG-1 inhibits epithelial-mesenchymal transition. The epithelial-mesenchymal transition (EMT) process is highly associated with enhanced mobility and invasiveness in carcinoma cells (28). Therefore, we investigated whether LRG-1 influences thyroid cancer cell EMT. qPCR and western blot analysis showed that LRG-1 depletion significantly changed the EMT phenotype by upregulating epithelial cell biomarkers (E-cadherin) and downregulating mesenchymal cell biomarkers (N-cadherin and vimentin) in HTC/C3 and SW579 cells (Fig. 3A and B). Furthermore, we examined the key transcription factors that govern the expression of EMT markers. As shown in Fig. 3C, SNAIL1, SNAIL2, ZEB1 and ZEB2 were all significantly decreased in LRG-1-knockdown cells. These findings indicate the promotive effect of LRG-1 on the EMT process in thyroid cancer cells.

MAPK/p38 signaling is critical for LRG-1-mediated EMT as well as migration and invasion capacity. Mitogen-activated protein kinases (MAPKs) are known to have important roles in cell migration and EMT processes $(29,30)$. Therefore, we assessed their roles in LRG-1-induced thyroid cancer cell EMT, migration and invasion. Western blot analysis demonstrated that LRG-1 (100-500 ng/ml) markedly increased p38 phosphorylation in a dose-dependent manner (Fig. 4A and $\mathrm{B}$ and Table SI). To confirm that LRG-1-induced EMT is dependent on the p38 pathway, a p38 inhibitor (p38-I) (SB203580, $10 \mu \mathrm{M}$ ) was used. Our data showed that the upregulation of the epithelial biomarker E-cadherin and the downregulation of the mesenchymal biomarkers $\mathrm{N}$-cadherin and vimentin triggered by LRG-1 $(500 \mathrm{ng} / \mathrm{ml})$ were reversed in the presence of a p38 inhibitor (Fig. 4C and D; Table SI). Additionally, inhibition of the p38 pathway by SB203580 also diminished LRG-1 (500 ng/ml)-induced SNAIL1, SNAIL2, ZEB1 and ZEB2 expression (Fig. 4E). Furthermore, when p38 phosphorylation was blocked in the wound healing and Transwell assays, the enhanced migration and invasion abilities of the thyroid cancer cells induced by LRG-1 (500 ng/ml) were almost completely abolished (Fig. 5 and Table SI). These data demonstrated that EMT and the cell migration and invasion-enhancing activities of LRG-1 are mediated by the MAPK/p38 pathway.

Knockdown of LRG-1 inhibits thyroid cancer growth in vivo. To detect the function of LRG-1 in the development of thyroid cancer in vivo, a nude mouse subcutaneously implanted tumor model was created. Our results demonstrated that nude mice injected with LRG-1-knockdown cells exhibited obviously decreased tumor volume at all examined time-points compared with nude mice injected with control scramble shRNA-infected cells (Fig. 6). The results indicated that the knockdown of LRG-1 significantly attenuated thyroid cancer growth in vivo.

\section{Discussion}

Recently, a growing number of studies have focused on discovering biomarkers and therapeutic targets of thyroid cancer (31). The major types of biomarkers include genetic markers, gene expression markers (mRNA and microRNA) and proteins (32). To date, the most important diagnostic markers are BRAFV600E, RAS mutations and RET-PTC and PAX8-PPAR $\gamma$ rearrangements (33). These novel markers are outstanding examples that have improved the diagnosis of thyroid nodules. In the present study, we identified leucine-rich-alpha-2-glycoprotein 1 (LRG-1) as a novel prognostic marker of thyroid cancer. Our data demonstrated that the mRNA and protein levels of LRG-1 were significantly increased in thyroid cancer tissues compared with those in normal tissues. In addition, high LRG-1 expression was a significant independent prognostic factor, and patients with higher LRG-1 levels suffered significantly worse disease-free survival.

As an increasing number of diagnostic markers and initiating oncogenic events have been revealed, molecular-targeted therapy holds great promise for aggressive and radioiodine-refractory thyroid cancers. A randomized phase II clinical trial demonstrated that vandetanib, a drug that targets the KDR, RET and EGFR kinases, produced a significant prolongation of median progression-free survival in aggressive differentiated thyroid cancer (34). Similarly, sorafenib (targets KDR, FLT4, RET and BRAF) (35) and lenvatinib (targets FLT1, KDR, FLT4, PDGFR and FGFR) (36), two additional kinase inhibitors, also prolonged progression-free survival in radioiodine-refractory differentiated thyroid cancer. In the present study, we observed that the knockdown of LRG-1 significantly inhibited thyroid cancer growth in vivo according to a nude mouse subcutaneously implanted tumor model. This result indicates that targeting LRG-1 may provide an efficient strategy for the treatment of thyroid cancer. It is of great importance to explore novel small-molecule agents targeting LRG-1 in the future.

Furthermore, our data demonstrated that LRG-1 significantly increases migration and invasion capacity with no effects on proliferation and apoptosis in thyroid cancer cells. These findings are consistent with those of previous publications, which demonstrated that LRG-1 promoted the migration and invasion capabilities of glioma cells (24), colorectal carcinoma cells (25) and human bone marrow mesenchymal stem cells (hBMMSCs) (37). The EMT process, in which cancer cells acquire a mesenchymal phenotype, has been proposed as a critical mechanism for the invasion and metastasis of cancers (38). Molecular changes in gene expression during EMT have been reported in thyroid carcinoma progression $(13,39)$. In the present study, we found that the thyroid cancer cell lines HTC/C3 and SW579 underwent EMT under the influence of LRG-1, with decreased expression of E-cadherin and increased expression of N-cadherin and vimentin. Similarly, Zhang et al showed that incubation of LRG-1 caused a shift from epithelial markers to mesenchymal markers, and Twist1, a well-known EMT-promoting transcriptional factor, was also found to be positively regulated by LRG-1 (25). In addition, LRG-1 also downregulated the expression of an epithelial marker (E-cadherin) in glioma cells (24). 
A
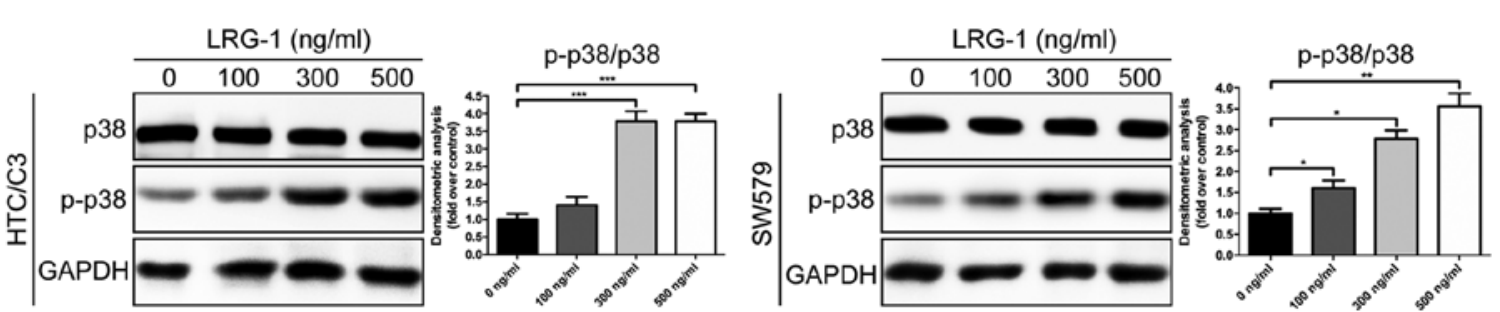

B
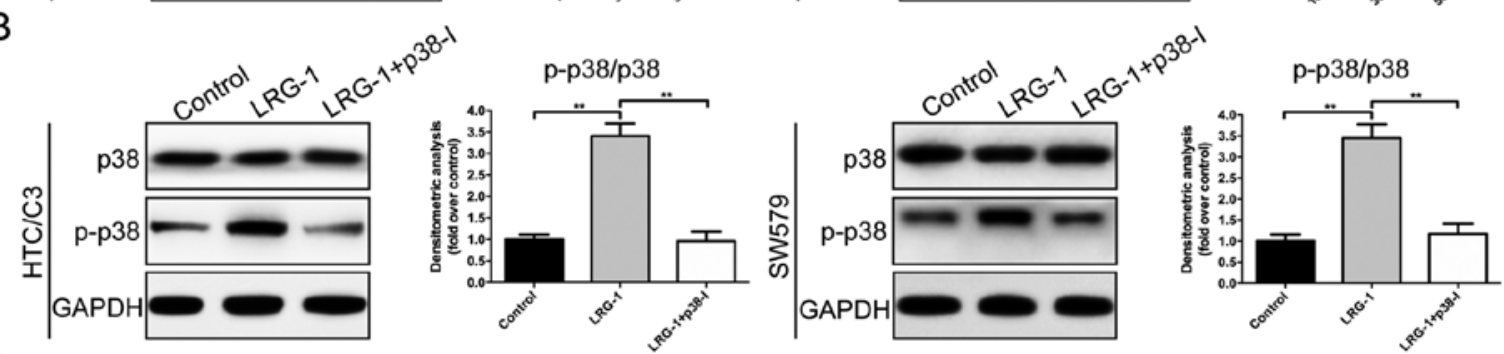

C
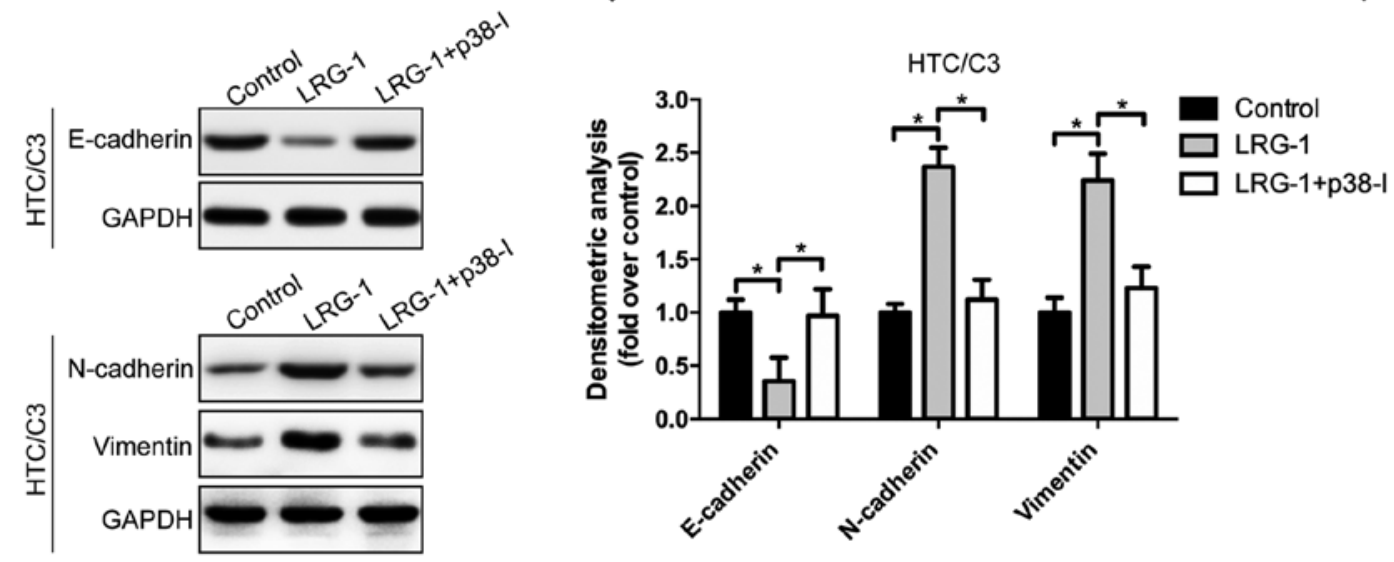

D
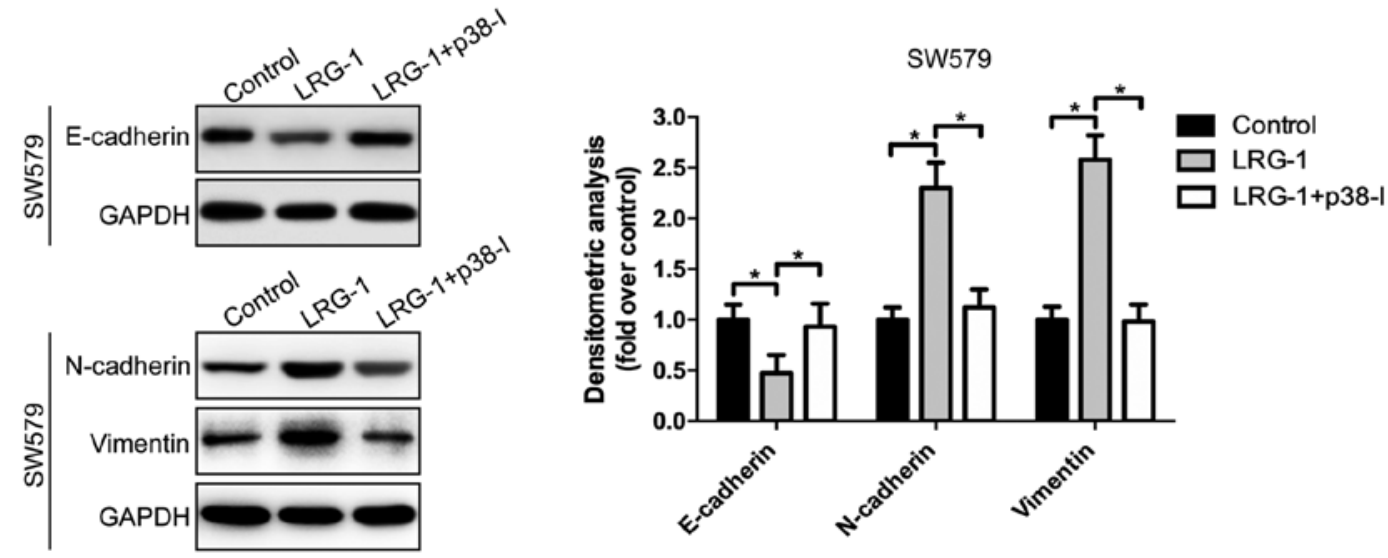

$\mathrm{E}$
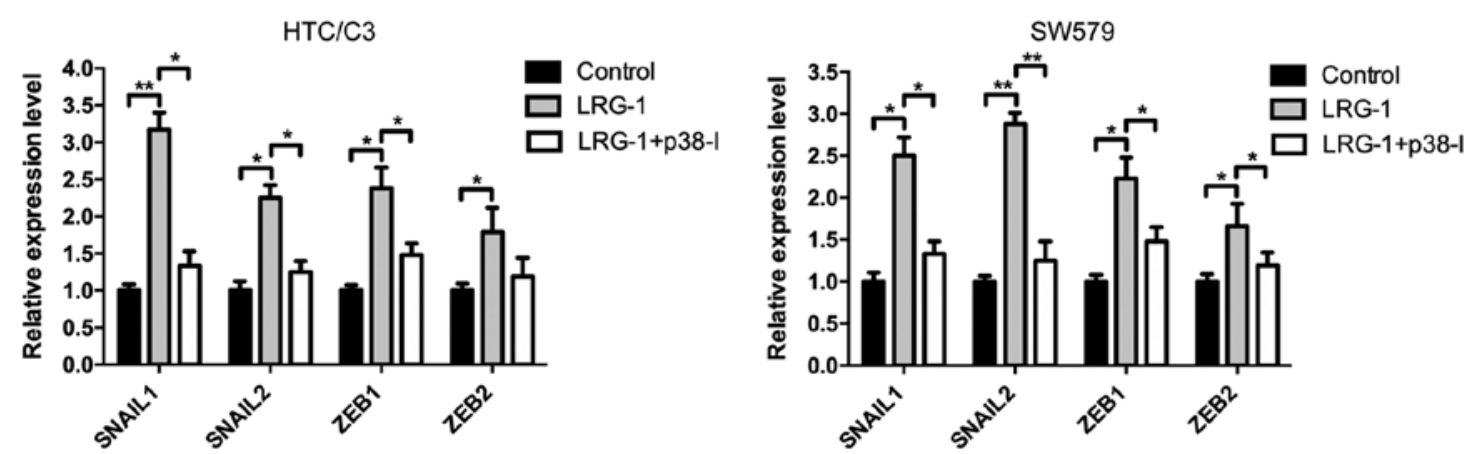

Figure 4. MAPK/p38 signaling is critical for LRG-1-mediated EMT. (A) Levels of p38 and phosphorylated p38 were assessed 15 min after LRG-1 treatment in the thyroid cancer HTC/C3 and SW579 cell lines. (B) Levels of p38 and p-p38 were examined after both cell lines were incubated with a p38 inhibitor (p38-I) (SB203580, $10 \mu \mathrm{M})$ and LRG-1 (500 ng/ml) for 15 min. (C and D) Levels of E-cadherin, N-cadherin and vimentin were examined after HTC/C3 and SW579 cells were incubated with p38-I (SB203580, $10 \mu \mathrm{M})$ and LRG-1 $(500 \mathrm{ng} / \mathrm{ml})$ for $15 \mathrm{~min}$. (E) Levels of SNAIL1, SNAIL2, ZEB1 and ZEB2 in thyroid cancer cells after incubation with p38-I $(10 \mu \mathrm{M})$ and LRG-1 $(500 \mathrm{ng} / \mathrm{ml})$ for 2 days. Data are presented as the mean $\pm \mathrm{SD}$ (three independent experiments). "P<0.05; ${ }^{* *} \mathrm{P}<0.01 ;{ }^{* * *} \mathrm{P}<0.001$. LRG-1, leucine-rich-alpha-2-glycoprotein 1; EMT, epithelial-mesenchymal transition. 
A
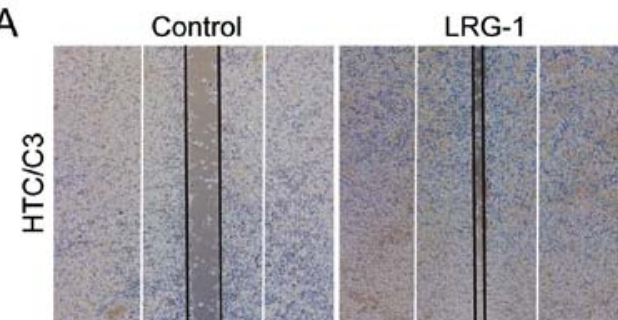

LRG-1+p38-I
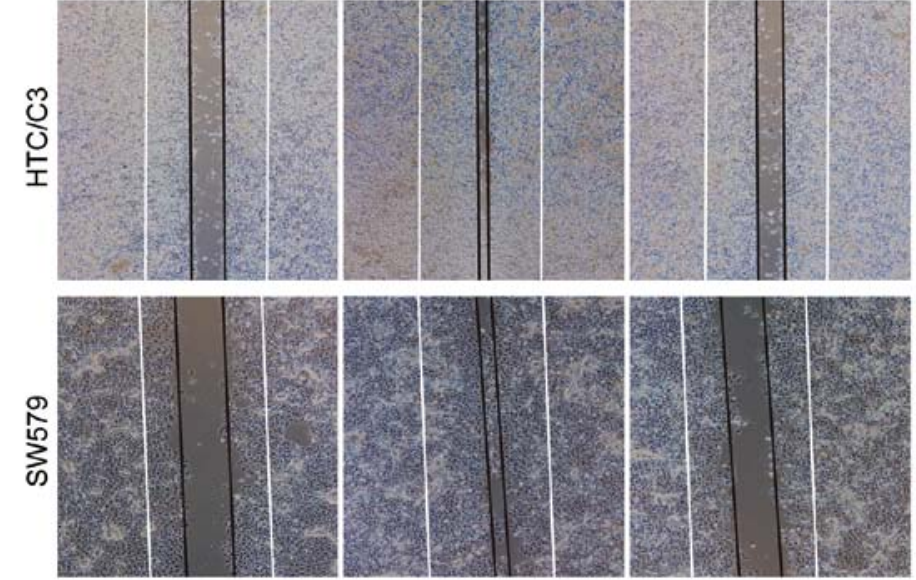

B
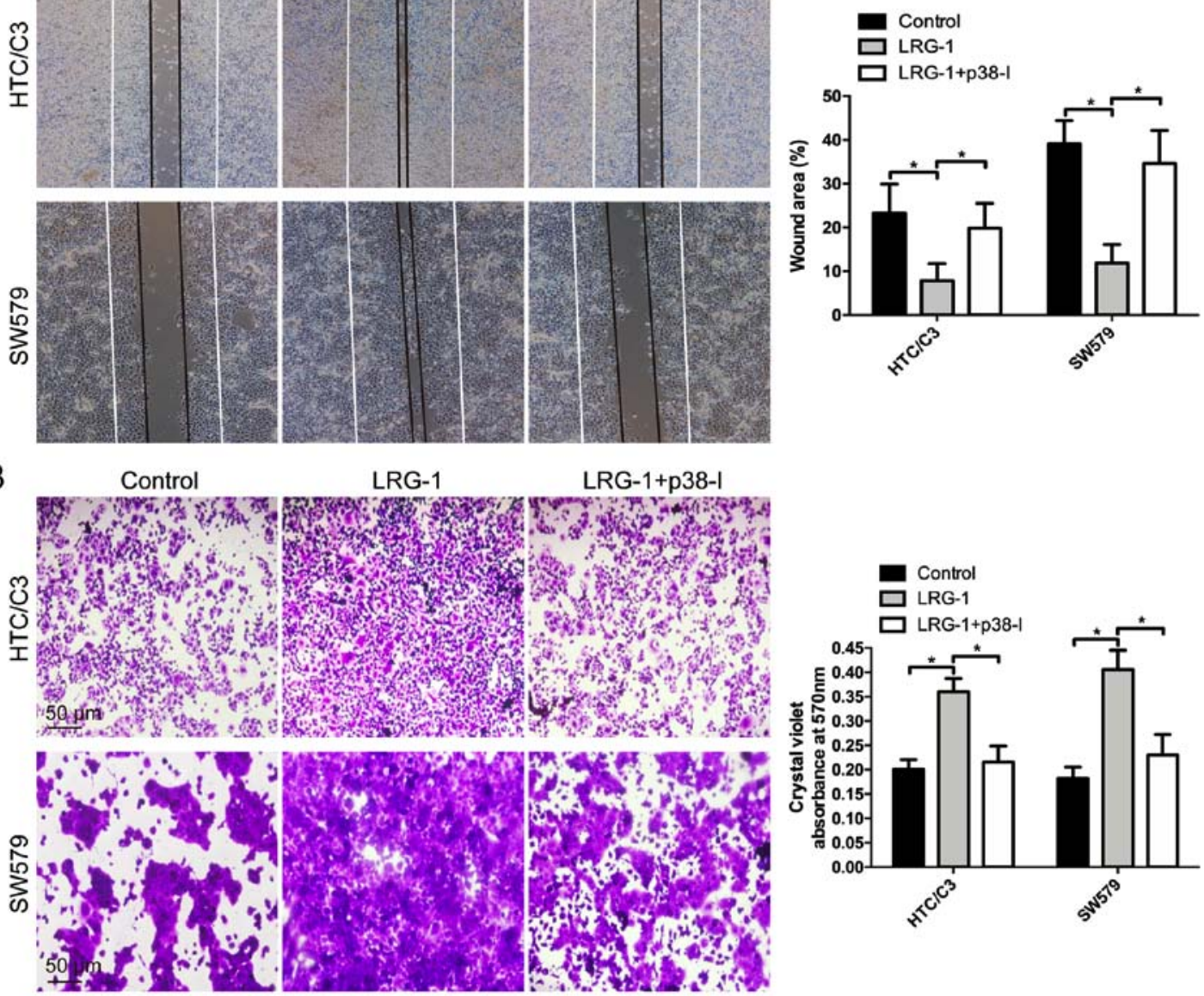

Figure 5. MAPK/p38 signaling plays a vital role in LRG-1-enhanced migration and invasion in thyroid cancer cells. (A) Wound-healing assay for the migration of thyroid cancer cells that were incubated with LRG-1 $(500 \mathrm{ng} / \mathrm{ml})$ or LRG-1 $(500 \mathrm{ng} / \mathrm{ml})+\mathrm{p} 38$ inhibitor $(\mathrm{p} 38-\mathrm{I})(10 \mu \mathrm{M})$. (B) Transwell assay for the invasion of thyroid cancer cells that were incubated with LRG-1 $(500 \mathrm{ng} / \mathrm{ml})$ or LRG-1 $(500 \mathrm{ng} / \mathrm{ml})+$ p38-I $(10 \mu \mathrm{M})$. Scale bars, $50 \mu \mathrm{m}$. Data are presented as the mean $\pm \mathrm{SD}$ (three independent experiments). ${ }^{*} \mathrm{P}<0.05$. LRG-1, leucine-rich-alpha-2-glycoprotein 1.

A

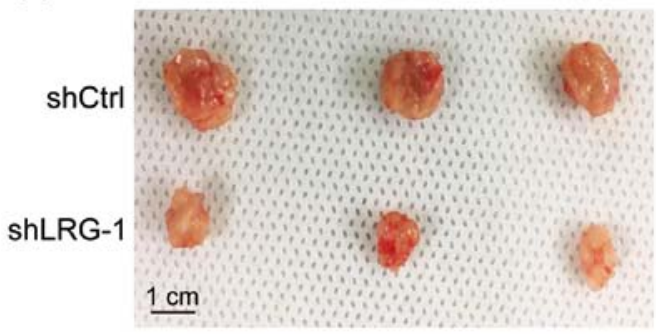

B

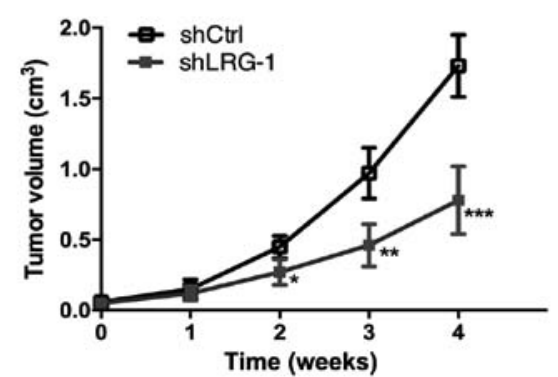

SW579

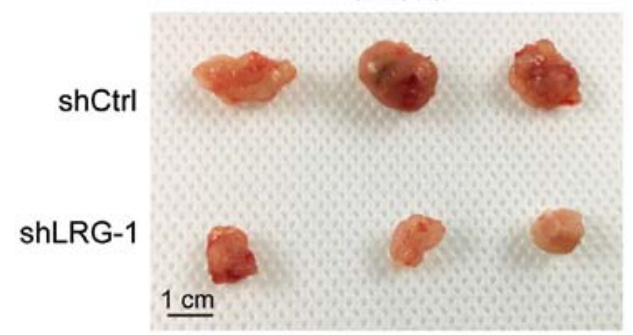

SW579

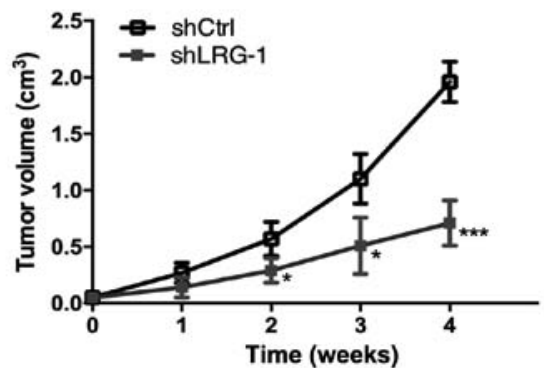

Figure 6. Knockdown of LRG-1 inhibits thyroid cancer growth in vivo. (A) Images of tumors at day 28 in the xenograft mouse model. (B) Tumor volume was measured using a caliper at the indicated time-points. Data are presented as the mean $\pm \mathrm{SD}$ (three independent experiments). ${ }^{*} \mathrm{P}<0.05 ;{ }^{* *} \mathrm{P}<0.01 ;{ }^{* * *} \mathrm{P}<0.001$. LRG-1, leucine-rich-alpha-2-glycoprotein 1. 
As it was demonstrated that LRG-1 enhances thyroid cancer cell migration, invasion and EMT, we next aimed to determine the underlying mechanisms. Multiple signaling pathways cooperate in the initiation and progression of EMT, and the MAPK pathway plays an essential role in this process $(30,40)$. MAPK can activate ETS1 and activated ETS1 cooperates with SNAIL1 to upregulate MMP expression (41). Similar to that of SNAIL, the stability of TWIST1 is regulated by MAPKs; MAPKs phosphorylate TWIST1 at Ser68, protecting it from ubiquitin-mediated degradation and increasing its activity (42). In addition, MAPK signaling increases TGF $\beta$-induced transcription, leading to increased repression of E-cadherin and the activation of $\mathrm{N}$-cadherin and MMP expression (43). Inhibition of ERK or p38 MAPK kinase activity represses the EMT process $(44,45)$. We found that LRG-1 upregulated the level of p38 phosphorylation in a dose-dependent manner. Furthermore, once the activity of p38 was attenuated by a specific inhibitor (SB203580), the biomarker and key transcription factors of the EMT process were obviously downregulated, and the enhanced migration and invasion ability of thyroid cancer cells induced by LRG-1 were almost completely abolished. Consistent with our findings, Wang et al demonstrated that LRG-1 promotes mesenchymal stem cell migration via activation of MAPK/p38 signaling (37). The EMT process in thyroid cancer was found to be characterized by a complex response involving multiple signaling pathways, such as Wnt/ $\beta$-catenin (14), MEK/ERK (17) and JAK/STAT pathways (46). Future investigations are necessary to elucidate how LRG-1 plays its role in these pathways, knowing that it could facilitate the further understanding of the bioactivity of LRG-1.

Although these findings are noteworthy, some limitations to this study must be recognized. In thyroid carcinogenesis, there is a stratification of the tumors based on the genetic background (BRAF, RAS or RET/PTC alterations). Therefore, in future research, it will be essential to investigate the relationship between the genetic background and LRG-1 expression in thyroid cancer since this may further elucidate the mechanisms regulating thyroid cancer formation and development.

In conclusion, the present study revealed that LRG-1 was overexpressed in thyroid cancer tissues and that high LRG-1 expression predicted poor patient survival and late tumor stage. LRG-1 significantly promoted the migration, invasion and EMT in thyroid cancer cells. This type of bioactivity of LRG-1 resulted from the enhancement of the MAPK/p38 signaling pathway. LRG-1 may serve as a promising biomarker for predicting prognosis in thyroid cancer patients, and LRG-1-based therapy may provide an efficient strategy for the treatment of aggressive thyroid cancer.

\section{Acknowledgements}

We are grateful to Dr Bo Zhang (Guangxi Medical University) for constructive comments on the manuscript.

\section{Funding}

No funding was received.

\section{Availability of data and materials}

The datasets used during the present study are available from the corresponding author upon reasonable request.

\section{Authors' contributions}

$\mathrm{ZB}$ and $\mathrm{ZX}$ conceived and designed the study. $\mathrm{ZB}, \mathrm{ZX}, \mathrm{JH}$, $\mathrm{ZT}$ and $\mathrm{LZ}$ contributed to the acquisition of the data. $\mathrm{ZB}, \mathrm{ZX}$, JH, ZT and LZ analyzed and interpreted the data. ZB and ZX wrote and revised the manuscript. ZX supervised the study. All authors read and approved the manuscript and agree to be accountable for all aspects of the research in ensuring that the accuracy or integrity of any part of the work are appropriately investigated and resolved.

\section{Ethics approval and consent to participate}

This study was approved by the Medical Ethics Committee of the Second Affiliated Hospital of Guangxi Medical University (no. 0010802). The study was performed in accordance with the ethical standards of the Declaration of Helsinki. Informed consent was obtained from all enrolled patients for the use of their tissues and clinicopathological data. All procedures for the animal experiments were approved by the Institutional Animal Care and Use Committee of Guangxi Medical University (no. 20186018S).

\section{Patient consent for publication}

Not applicable.

\section{Competing interests}

The authors declare that they have no competing interests.

\section{References}

1. Yapa S, Mulla O, Green V, England J and Greenman J: The role of chemokines in thyroid carcinoma. Thyroid 27: 1347-1359, 2017.

2. Lim H, Devesa SS, Sosa JA, Check D and Kitahara CM: Trends in thyroid cancer incidence and mortality in the United States, 1974-2013. JAMA 317: 1338-1348, 2017.

3. Haugen BR, Alexander EK, Bible KC, Doherty GM, Mandel SJ, Nikiforov YE, Pacini F, Randolph GW, Sawka AM, Schlumberger M, et al: 2015 American thyroid association management guidelines for adult patients with thyroid nodules and differentiated thyroid cancer: The American thyroid association guidelines task force on thyroid nodules and differentiated thyroid cancer. Thyroid 26: 1-133, 2016.

4. Ibrahim EY and Busaidy NL: Treatment and surveillance of advanced, metastatic iodine-resistant differentiated thyroid cancer. Curr Opin Oncol 29: 151-158, 2017.

5. Nikiforov YE: Role of molecular markers in thyroid nodule management: Then and now. Endocr Pract 23: 979-988, 2017.

6. Romei C, Ciampi R and Elisei R: A comprehensive overview of the role of the RET proto-oncogene in thyroid carcinoma. Nat Rev Endocrinol 12: 192-202, 2016.

7. Bogachek MV, De Andrade JP and Weigel RJ: Regulation of epithelial-mesenchymal transition through SUMOylation of transcription factors. Cancer Res 75: 11-15, 2015.

8. Huang RY, Guilford P and Thiery JP: Early events in cell adhesion and polarity during epithelial-mesenchymal transition. J Cell Sci 125: 4417-4422, 2012.

9. Kalluri R and Weinberg RA: The basics of epithelial-mesenchymal transition. J Clin Invest 119: 1420-1428, 2009. 
10. Lamouille S, Xu J and Derynck R: Molecular mechanisms of epithelial-mesenchymal transition. Nat Rev Mol Cell Biol 15: 178-196, 2014

11. Tam WL and Weinberg RA: The epigenetics of epithelial-mesenchymal plasticity in cancer. Nat Med 19: 1438-1449, 2013

12. Thiery JP, Acloque H, Huang RY and Nieto MA: Epithelialmesenchymal transitions in development and disease. Cell 139: 871-890, 2009.

13. Vasko V,Espinosa AV, Scouten W, He H, Auer H, Liyanarachchi S, Larin A, Savchenko V, Francis GL, de la Chapelle A, et al: Gene expression and functional evidence of epithelial-to-mesenchymal transition in papillary thyroid carcinoma invasion. Proc Natl Acad Sci USA 104: 2803-2808, 2007.

14. Chen LL, Gao GX, Shen FX, Chen X, Gong XH and Wu WJ: SDC4 gene silencing favors human papillary thyroid carcinoma cell apoptosis and inhibits epithelial mesenchymal transition via Wnt/ $\beta$-catenin pathway. Mol Cells 41: 853-867, 2018.

15. Puli OR, Danysh BP, McBeath E, Sinha DK, Hoang NM, Powell RT, Danysh HE, Cabanillas ME, Cote GJ and Hofmann MC: The transcription factor ETV5 mediates BRAFV600E-induced proliferation and TWIST1 expression in papillary thyroid cancer cells. Neoplasia 20: 1121-1134, 2018.

16. Yan R, Yang T,Zhai H,Zhou Z, Gao L and Li Y: MicroRNA-150-5p affects cell proliferation, apoptosis, and EMT by regulation of the BRAF ${ }^{\mathrm{V} 600 \mathrm{E}}$ mutation in papillary thyroid cancer cells. J Cell Biochem 119: 8763-8772, 2018.

17. Wang $Y, G u ~ J$, Lin X, Yan W, Yang W and Wu G: IncRNA BANCR promotes EMT in PTC via the Raf/MEK/ERK signaling pathway. Oncol Lett 15: 5865-5870, 2018.

18. Haupt $\mathrm{H}$ and Baudner $\mathrm{S}$ : Isolation and characterization of an unknown, leucine-rich 3.1-S-alpha2-glycoprotein from human serum (author's trans1). Hoppe Seylers Z Physiol Chem 358: 639-646, 1977 (In German).

19. Wang X, Abraham S, McKenzie JAG, Jeffs N, Swire M, Tripathi VB, Luhmann UFO, Lange CAK, Zhai Z, Arthur HM, et al: LRG1 promotes angiogenesis by modulating endothelial TGF-beta signalling. Nature 499: 306-311, 2013.

20. Furukawa K, Kawamoto K, Eguchi H, Tanemura M, Tanida T, Tomimaru Y, Akita H, Hama N, Wada H, Kobayashi S, et al: Clinicopathological significance of leucine-rich $\alpha 2$-glycoproteinin sera of patients with pancreatic cancer. Pancreas 44: 93-98, 2015

21. Lindén M, Lind SB, Mayrhofer C, Segersten U, Wester K, Lyutvinskiy Y, Zubarev R, Malmström PU and Pettersson U: Proteomic analysis of urinary biomarker candidates for nonmuscle invasive bladder cancer. Proteomics 12: 135-144, 2012.

22. Andersen JD, Boylan KL, Jemmerson R, Geller MA, Misemer B, Harrington KM, Weivoda S, Witthuhn BA, Argenta P, Vogel RI and Skubitz AP: Leucine-rich alpha-2-glycoprotein-1 is upregulated in sera and tumors of ovarian cancer patients. J Ovarian Res 3: 21, 2010

23. Sandanayake NS, Sinclair J, Andreola F, Chapman MH, Xue A, Webster GJ, Clarkson A, Gill A, Norton ID, Smith RC, et al: A combination of serum leucine-rich $\alpha$-2-glycoprotein 1, CA19-9 and interleukin- 6 differentiate biliary tract cancer from benign biliary strictures. Br J Cancer 105: 1370-1378, 2011

24. Zhong D, He G, Zhao S, Li J, Lang Y, Ye W, Li Y, Jiang C and Li X: LRG1 modulates invasion and migration of glioma cell lines through TGF- $\beta$ signaling pathway. Acta Histochem 117: $551-558,2015$

25. Zhang J, Zhu L, Fang J, Ge Z and Li X: LRG1 modulates epithelial-mesenchymal transition and angiogenesis in colorectal cancer via HIF-1 $\alpha$ activation. J Exp Clin Cancer Res 35: 29, 2016

26. Livak KJ and Schmittgen TD: Analysis of relative gene expression data using real-time quantitative PCR and the $2^{-\Delta \Delta C_{\mathrm{T}}}$ method. Methods 25: 402-408, 2001.

27. Alegria-Schaffer A, Lodge A and Vattem K: Performing and optimizing Western blots with an emphasis on chemiluminescent detection. Methods Enzymol 463: 573-599, 2009.

28. Meng X, Kong DH, Li N, Zong ZH, Liu BQ, Du ZX, Guan Y, Cao L and Wang HQ: Knockdown of BAG3 induces epithelial-mesenchymal transition in thyroid cancer cells through ZEB1 activation. Cell Death Dis 5: e1092, 2014.

29. Huang C, Jacobson $\mathrm{K}$ and Schaller MD: MAP kinases and cell migration. J Cell Sci 117: 4619-4628, 2004.
30. Okada T, Sinha S, Esposito I, Schiavon G, López-Lago MA, Su W, Pratilas CA, Abele C, Hernandez JM, Ohara M, et al: The Rho GTPase Rnd1 suppresses mammary tumorigenesis and EMT by restraining Ras-MAPK signalling. Nat Cell Biol 17: 81-94, 2015.

31. Hu Y, Wang H, Chen E, Xu Z, Chen B and Lu G: Candidate microRNAs as biomarkers of thyroid carcinoma: A systematic review, meta-analysis, and experimental validation. Cancer Med 5: 2602-2614, 2016.

32. Xing M, Haugen BR and Schlumberger M: Progress in molecular-based management of differentiated thyroid cancer. Lancet 381: 1058-1069, 2013.

33. Nikiforov YE, Ohori NP, Hodak SP, Carty SE, LeBeau SO, Ferris RL, Yip L, Seethala RR, Tublin ME, Stang MT, et al: Impact of mutational testing on the diagnosis and management of patients with cytologically indeterminate thyroid nodules: A prospective analysis of 1056 FNA samples. J Clin Endocrinol Metab 96: 3390-3397, 2011

34. Leboulleux S, Bastholt L, Krause T, de la Fouchardiere C, Tennvall J, Awada A, Gómez JM, Bonichon F, Leenhardt L, Soufflet $\mathrm{C}$, et al: Vandetanib in locally advanced or metastatic differentiated thyroid cancer: A randomised, double-blind, phase 2 trial. Lancet Oncol 13: 897-905, 2012.

35. Kloos RT, Ringel MD, Knopp MV, Hall NC, King M, Stevens R, Liang J, Wakely PE Jr, Vasko VV, Saji M, et al: Phase II trial of sorafenib in metastatic thyroid cancer. J Clin Oncol 27: 1675-1684, 2009.

36. Sherman SI, Jarzab B, Cabanillas ME, Licitra LF, Pacini F, Martins R, Robinson B, Ball D, McCaffrey J, Shah MH, et al: A phase II trial of the multi-targeted kinase inhibitor, lenvatinib (E7080), in advanced radioiodine-refractory differentiated thyroid cancer (DTC). J Clin Oncol 29 (Suppl): S5503, 2011.

37. Wang Y, Xu J, Zhang X, Wang C, Huang Y, Dai K and Zhang X: TNF- $\alpha$-induced LRG1 promotes angiogenesis and mesenchymal stem cell migration in the subchondral bone during osteoarthritis. Cell Death Dis 8: e2715, 2017.

38. Yang $\mathbf{J}$ and Weinberg RA: Epithelial-mesenchymal transition: At the crossroads of development and tumor metastasis. Dev Cell 14: 818-829, 2008.

39. Hardy RG, Vicente-Dueñas C, González-Herrero I, Anderson C, Flores T, Hughes S, Tselepis C, Ross JA and Sánchez-García I: Snail family transcription factors are implicated in thyroid carcinogenesis. Am J Pathol 171: 1037-1046, 2007.

40. Mulholland DJ, Kobayashi N, Ruscetti M,Zhi A, Tran LM,Huang J, Gleave $\mathrm{M}$ and Wu H: Pten loss and RAS/MAPK activation cooperate to promote EMT and metastasis initiated from prostate cancer stem/progenitor cells. Cancer Res 72: 1878-1889, 2012.

41. Jordà $\mathrm{M}$, Olmeda $\mathrm{D}$, Vinyals $\mathrm{A}$, Valero $\mathrm{E}$, Cubillo $\mathrm{E}$, Llorens $\mathrm{A}$, Cano A and Fabra A: Upregulation of MMP-9 in MDCK epithelial cell line in response to expression of the Snail transcription factor. J Cell Sci 118: 3371-3385, 2005.

42. Hong J, Zhou J, Fu J, He T, Qin J, Wang L, Liao L and Xu J: Phosphorylation of serine 68 of Twist 1 by MAPKs stabilizes Twist 1 protein and promotes breast cancer cell invasiveness. Cancer Res 71: 3980-3990, 2011.

43. Uttamsingh S, Bao X, Nguyen KT, Bhanot M, Gong J, Chan JL, Liu F, Chu TT and Wang LH: Synergistic effect between EGF and TGF-beta1 in inducing oncogenic properties of intestinal epithelial cells. Oncogene 27: 2626-2634, 2008.

44. Xie L, Law BK, Chytil AM, Brown KA, Aakre ME and Moses HL: Activation of the Erk pathway is required for TGF-beta1-induced EMT in vitro. Neoplasia 6: 603-610, 2004.

45. Yu L, Hébert MC and Zhang YE: TGF-beta receptor-activated p38 MAP kinase mediates Smad-independent TGF-beta responses. EMBO J 21: 3749-3759, 2002.

46. Bi CL, Zhang YQ, Li B, Guo M and Fu YL: MicroRNA-520a-3p suppresses epithelial-mesenchymal transition, invasion, and migration of papillary thyroid carcinoma cells via the JAK1-mediated JAK/STAT signaling pathway. J Cell Physiol 234: 4054-4067, 2019.

This work is licensed under a Creative Commons Attribution-NonCommercial-NoDerivatives 4.0 International (CC BY-NC-ND 4.0) License. 